\title{
Mito e gênero: \\ Pandora e Eva em perspectiva histórica comparada"
}

\author{
Andréia Cristina Lopes Frazão da Silva* \\ Marta Mega de Andrade***
}

\section{Resumo}

Neste artigo, discutimos as potencialidades teórico-metodológicas dos estudos de gênero na perspectiva da História Comparada. A partir da análise de enunciações dos mitos de Pandora e Eva, focalizamos uma problemática do gênero associada à tematização do corpo e do casamento na Atenas Clássica (apropriações das narrativas do mito de Pandora por Hesíodo) e no Reino de Portugal em fins do medievo, analisando como a diferença é significada, questionada e legitimada nestes dois contextos históricos distintos.

Palavras-chave: Estudos de Gênero, Grécia Antiga, Portugal Medieval, Eva, Pandora.

\footnotetext{
* Recebido para publicação em 23 de janeiro de 2008, aceito em 28 de fevereiro de 2009.

** Professora Associada do Programa de Estudos Medievais, IFCS, Universidade Federal do Rio de Janeiro. andreiafrazao@terra.com.br

**** Professora Adjunta do Laboratório de História Antiga, LHIA, IFCS, Universidade Federal do Rio de Janeiro. martamega@gmail.com
} 


\author{
Myth and Gender: \\ Pandora and Eva in a Comparative Historical Approach
}

\begin{abstract}
In this article, we discuss theoretical and methodological potentials of gender studies in Comparative History. By analyzing enunciations of Pandora's (Hesiod's Theogony and Works and Days) and Eva's (version of the medieval Portuguese Bible) myths, we focus on gender issues associated to body and marriage in ancient Greece (classical Athens) and in the kingdom of Portugal at the end of Middle Ages. Our interest lies on how difference is signified, questioned and legitimated in relation to these two distinct historical contexts.
\end{abstract}

Key Words: Gender Studies, Ancient Greece, Medieval Portugal, Eva, Pandora. 
Comparar Eva e Pandora não é um exercício original. Nos últimos anos, trabalhos acadêmicos em diversas áreas dedicaramse a essa tarefa. Especialistas em estudos clássicos procuraram aproximar os mitos ${ }^{1}$, enquanto os teólogos mais recentes questionaram a relação direta entre as narrativas, introduzindo a questão da apropriação ocidental. ${ }^{2}$ Neste contexto, o artigo de P. Schmitt-Pantel sobre os mitos de Pandora e Eva, publicado no Brasil em 2001, busca "recordar a utilização feita dos relatos míticos de criação para construir a diferença dos sexos própria de cada cultura e de cada sociedade" (Schmitt-Pantel, 2001:129) e verificar como a crítica feminista se posiciona face a tais relatos, relacionando assim mito e história. Esse artigo é particularmente relevante para as nossas reflexões, na medida em que introduz, como parte da produção do conhecimento historiográfico sobre os mitos, a crítica do próprio contexto (social) de produção dos mesmos, envolvendo as conclusões dos especialistas modernos, questionando "se" o movimento feminista debateu o tema: a saber, as relações de dominação consagradas por esses mitos e recontadas desde tempos imemoriais. Inclui, ainda, outro aspecto da

1 Como L. Séchan, que em artigo publicado em 1929 defendeu que ambos os mitos foram redigidos com o intuito de construir uma visão negativa sobre as mulheres. W. Headlam, em 1934, afirmou que os mitos de Pandora e Eva eram duas variações de uma história primitiva sobre a criação da primeira mulher. F. Teggart, pautado na estrutura das obras, corroborou essa tese ao afirmar que "Hesiod had made use of some variant of narrative that was also utilized in the story of the Garden of Eden" (1947).

2 Ver S. Lachs (1974) que, sem propriamente negar a relação entre as narrativas, analisou o emprego das figuras de Pandora e de Eva na literatura rabínica elaborada no fim da Antiguidade e início da Idade Média. Já W. E. Phipps (1988) defendeu não haver qualquer relação originária entre os mitos de Pandora e Eva. A vinculação desses dois mitos, argumenta o autor, foi elaborada pelas leituras ocidentais posteriores. Por fim, destacamos a coletânea publicada em 2001 em Paris, sob a direção de J-C. Schmitt, intitulada Éve et Pandora. La création de la femme, Essa obra retoma, de certa forma, a tradição literária anterior a 1960, mas com um escopo comparativo envolvendo as diversas formas de representação artística e literária das figuras conjugadas de Pandora e de Eva. 
questão: essas narrativas institucionalizadas têm peso na vida cotidiana das mulheres, divididas em contextos complexos que envolvem etnias, classes, nacionalidades, além das crenças? Como esses mitos são, hoje, re-apropriados pelos agentes sociais? E eles o são? Fazem algum sentido?

Nos diversos trabalhos que procuraram contrapor Pandora $e$ Eva, percebemos duas grandes linhas interpretativas: uma que busca acentuar as similitudes entre os mitos e outra que sublinha as diferenças. Nossa abordagem, embora tributária desses estudos, afasta-se um pouco para analisar comparativamente os usos de tais mitos em dois contextos históricos diferentes - Atenas Clássica e Portugal entre os séculos XIII e XIV. Não se trata, portanto, de Literatura, de Teologia, ou de Mitologia Comparada, mas de um exercício historiográfico. Isto significa que, primeiramente, interessam-nos não tanto os mitos como textos - que, aliás, pode não ter sido seu principal modo de circulação nos períodos considerados - mas as suas enunciações em dados momentos da história, como discursos vinculados a certas práticas. No caso da Atenas Clássica, por exemplo, a tentativa de imposição de papéis cristalizados de gênero, dentro de um projeto (político) em uma sociedade patrimonial. No caso de Portugal, nos séculos XIII e XIV, focalizamos a produção discursiva de um projeto de identidade de gênero.

Em segundo lugar, consideramos a validade de realizar um estudo comparado de Pandora e Eva, pois essas figuras femininas paradigmáticas são um ponto de partida privilegiado para desenvolver os usos teóricos da noção de gênero como saber $e$ discurso e para explorar um pouco as possibilidades da História Comparada.

\section{Gênero, Mito e História Comparada: reflexões teóricas}

Em um trabalho amplamente debatido em nosso meio, Gender as a Useful Category of Historical Analysis, a historiadora 
norte-americana Joan Scott propõe uma definição dupla de gênero e analisa seus desdobramentos. Ela afirma que gênero é saber construído a partir das diferenças percebidas entre os sexos $e$, depois, que gênero é forma primária de dar significado a relações de poder (Scott, 1999:42).

Essa ordem nas definições sugere a construção simultânea $e$ imanente do saber e da organização das relações de poder, subvertendo teses que compreendem as relações de gênero como expressões dos fundamentos materiais de uma sociedade de classes. No caso de Bourdieu (2002), por exemplo, a análise da dominação masculina assenta o fenômeno nas relações sócioeconômicas de exploração, perpassando os diversos nós da rede social, separando os sujeitos entre proprietários e expropriados, fortes e fracos, ativos e passivos, gerando uma escala de valores que contribui para reproduzir cotidianamente um status quo.

Com sua crítica a essas e outras abordagens do gênero, Joan Scott aponta para o fato de que a percepção da diferença pode ser primária. Ou seja, pode ser propriamente uma parte fundamental dessas condições da existência que estruturam valores, tornando possível todo o discurso sobre a diferença, logo, sobre a desigualdade em quaisquer de suas formas. O saber se produz, assim, no encontro - que só pode ser material - das pessoas e das coisas (não a partir do, mas no encontro) e na percepção de que os seres existem diferentemente. Melhor dizendo, torna pensável a própria diferença, a alteridade, e daí a di-visão social.

Gênero, então, como aquilo que torna pensável, que permite pensar, é propriamente um saber. O curioso é que saber não é em absoluto um conhecimento, nem mesmo um reconhecimento, não é um "dito", embora organize o "dizer" e a experiência sem transcendê-los. O saber é físico, carnal, humano, histórico, dinâmico. Aí nos desvinculamos da tradição que liga saber a este ou aquele "discurso", como sinônimo de "fato lingüístico", como se o mundo "letrado" fosse seu (único) universo. Necessárias essas considerações iniciais, pois vamos falar 
de leitura histórica comparada de mitos. Destacamos de antemão que não partimos da perspectiva de que os mitos são estruturas que exprimem, alegórica ou tautologicamente, formas puras essenciais da natureza humana. $\mathrm{O}$ que se expressa com uma narrativa mítica é um encontro singular de perspectivas sobre o "real" e a vida, enfim, um saber. Ora, aquilo que se sabe com um mito é real justamente quando as palavras são pronunciadas, seja pelo aedo, pelo monarca, pelo chefe ou sacerdote. É inerente à natureza do significado (sempre contextual), produzido pela narrativa mítica, o fato de esgotar-se no próprio ato de sua enunciação $e$ "consumo" pelos ouvintes. Isto coloca o mito diretamente sob a luz da historicidade de seus modos de apropriação, o que torna sua análise, sem nenhuma dúvida, bem mais complicada; vital, contudo, para uma leitura que objetive comparar sociedades, mais do que textos.

No nosso caso em particular, como assinalamos, essas sociedades se situam na Atenas Clássica e em Portugal Medieval. ${ }^{3}$ Tendo como foco as relações de gênero, é inegável que as enunciações dos mitos selecionados reforçaram as assimetrias entre homens e mulheres de um modo geral. Contudo, de que forma o fizeram? Como foram construídos os argumentos que justificaram essa assimetria? O que significa, para cada caso em foco, assimetria? Como o gênero opera historicamente nesses mitos? Comparando, é possível verificar as múltiplas particularidades e variedades do que pareceria, de outro modo, constante. $\mathrm{E}$ isto tanto no que diz respeito à longa duração dos mitos e textos estudados, quanto no que se refere a certos "invariantes" que precisamos, mais do que nunca, mobilizar: homem, mulher, dominação, etc. Assim, através da comparação, verificam-se as similaridades $e$ as diferenças entre os fenômenos: por um lado, constroem-se interdependências e verificam-se

3 É sempre um movimento difícil este de definir em um espaço restrito o recorte da sociedade que abordamos. Atenas Clássica e Portugal Medieval devem ser tomados aqui como horizontes da investigação, mais do que realidades homogêneas, containers daquilo que será explicitado. 
constâncias, como sugere Veyne (1983:15); por outro, quebram-se continuidades, cortam-se emaranhamentos, e interrompe-se o fluxo da narração (Kocka, 2003:41).

O texto das narrativas hesiódicas para o público de língua portuguesa encontra-se, hoje, em forma de livro, edição bilingüe grego/português, com tradução de dois especialistas em filologia e literatura grega antiga. Diante desse livro, lendo-o, fazendo anotações e adotando estratagemas para torná-lo familiar a nós mesmos, o que significa aos nossos dilemas, é forçoso constatar que estamos não somente diante do muthos cantado pelo poeta beócio por volta de 750 a.C., mas principalmente diante de narrativas que tem uma vida entre nós, uma atualidade e um valor. O livro, objeto da legitimidade no campo do saber acadêmico e universitário sobre a literatura grega, assume para nós a forma canônica de uma literatura que deve ser interpretada, cujas relações com nosso meio historiográfico não são dadas de forma "aproblemática". Assim, desfazer o "fetiche" do livro, da escritura, é o primeiro passo para a compreensão da história de Pandora e Prometeu.

Sem o suporte bibliográfico, a história deve ser pressuposta. É claro que alguns meios a preservaram por escrito, pois, de outra forma, os poemas de Hesíodo não teriam sobrevivido, como muitas outras obras. Mas esses meios eram minoritários, e, diferentemente da Igreja Romana Medieval, não tinham a intenção de espalhar uma espécie de "doutrina" convertendo fiéis. Contudo, não tenhamos a impressão de que as histórias de Hesíodo circulavam de modo restrito. Sabemos, por outros testemunhos, como a iconografia (da arte em geral) e as peças de teatro, que os atenienses não apenas conheciam o mito de Pandora, como procuraram apropriar-se da figura da primeira mulher. Deram-lhe morada na iconografia e no coração mesmo da ideologia da autoctonia (Loraux, 1990), pela qual os e as atenienses deveriam reconhecer seu enraizamento na terra dos pais, a patrís (outro modo de dizer "polis"). 
Se levarmos em consideração os textos da Atenas Clássica, observaremos a presença não de Pandora, mas de seus atributos femininos. Falar do que é próprio ao feminino comporta duas vias, um modelo e um anti-modelo, um positivo e um negativo. De um lado, a boa esposa, ou mélissa; do outro, a mulher feminina, este ser meio-humano que descende da raça das mulheres, génos gunaikon. A ambigüidade entre a boa esposa e a mulher desmedida, tema largamente explorado nas tragédias atenienses, é tributária da construção hesiódica de Pandora (mal reverso de um bem, como veremos adiante), demonstrando, assim, que atribuir feminilidade pode ser, na Atenas Clássica, correlativo ao apropriar-se da tradição hesiódica (Andrade, 2001).

Poderíamos dizer que a figura de Pandora - bem como a narrativa de sua criação compilada por Hesíodo - forneceu o lugar objetivo a partir do qual pôde ser proposta, com clareza, a questão do feminino na Atenas Clássica? Interessante aqui é notar que, se não podemos reduzir toda a compreensão do feminino na cultura grega ao espelho de Pandora, podemos, com propriedade, oferecer esse espelho às mulheres de Atenas, pretensamente "cidadãs". O modelo da boa esposa, por exemplo, é ideal normativo da sociedade políade ateniense ao longo de todo o período clássico; mas não o foi antes, nem o será depois. $\mathrm{O}$ historiador americano J. Redfield (1994:147-171) já havia apontado que a cultura políade da Atenas clássica praticamente exilou de seus textos as histórias de amor, ou melhor, a visão positiva do casamento. E com isso, a visão positiva da relação marido-esposa, como a que funda a história de Penélope e Odisseus, tradição da epopéia grega, bem anterior aos poemas de Hesíodo. Dessa maneira, Redfield estabelece uma relação direta entre a desvalorização da mulher e do casamento e o apogeu da polis como espaço político de homens livres, autóctones e iguais. Concordamos com a sugestão de Redfield, de que há uma ligação direta entre o exercício do poder no âmbito da polis ateniense e a busca de papéis delimitados de gênero, que é ainda a busca de uma separação contundente entre masculino e feminino, por um 
lado, além do aprisionamento dos atributos femininos em um jogo de ambigüidades, por outro. A relação do mito de Pandora com a Atenas Clássica deve ser discutida a partir desse contexto.

Quanto à figura de Eva, como já assinalamos, optamos por analisar os capítulos referentes à criação de Adão e Eva de uma versão medieval da Bíblia, redigida em português. Tal texto encontrava-se no códice 349 da Biblioteca do Mosteiro de Alcobaça, denominado como Historias d'abreviado testamento velho, segundo o meestre das Historias Scolasticas, e segundo outros, que as abreviarom, e com dezeres d'alguns doctores $e$ sabedores (Nascimento, 2000:90). Esse manuscrito está atualmente perdido $e$ foi preservado pela edição elaborada pelo Frei Fortunato de São Boaventura em 1829.

Para Frei Fortunato, a obra é de 1320, mas suspeita que se originou de um modelo do século anterior. Segundo Antunes, no inventário dos Códices Alcobacenses do século XIII, o códice 349 já figura (Antunes, 2000:85). Assim, é possível supor que a composição dessa versão medieval portuguesa do Antigo Testamento date do final do século XIII.

Segundo Heitor Megale, a obra não é uma tradução da Vulgata, mas uma versão da Historia Scholastica de Pedro Comestor. Contudo, comparando o texto de Comestor ao da Bíblia portuguesa, percebem-se muitas diferenças, a começar pela organização dos capítulos. Além disso, o texto português é mais sintético. O próprio título do manuscrito sublinha que o texto é fruto de um conjunto de fontes distintas: a obra de Comestor, seus glosadores e "dezeres de doctores e sabedores". Ou seja, ainda que se mantenha fiel, em linhas gerais, à narrativa bíblica, já bastante divulgada no período, o texto em análise apresenta elementos inovadores, tais como uma nova organização de capítulos, simplificações, inserção de detalhes, elaboração de associações e interpretações de alguns fatos, etc. Há que destacar, contudo, que independente da origem do texto, trata-se de uma leitura medieval do mito da criação, enunciada no Reino de Portugal em fins do século XIII. 
Essa versão portuguesa da Bíblia, apesar de suas funções religiosas e didáticas, possuía um caráter culto, como é possível inferir pela presença de idéias aristotélicas e de dados astronômicos, geográficos e químicos. O público alvo era, certamente, formado por religiosos, estudantes e pregadores. Sua transmissão no período foi prioritariamente pela via escrita, para a leitura privada e/ou consulta para o preparo de sermões e demais textos. Vale destacar que autores dos mais diversos tipos de obras literárias compostas em Portugal nos séculos finais da Idade Média - como cantigas, hagiografias, sermões, crônicas, etc. - fizeram referências diretas ou indiretas ao texto bíblico, o que corrobora a hipótese da grande divulgação da Bíblia no período, provavelmente em diferentes versões e formas (Martins, 1979). Uma delas foi o nosso "testamento velho".

Esse texto foi traduzido e começou a circular em Portugal em um momento marcado pelas tentativas do papado para introduzir seu modelo de organização eclesiástica em todo o Ocidente; pela expansão das ordens mendicantes; pela multiplicação dos centros de saber urbano; pelo reinado de D. Diniz, que introduziu reformas e estimulou a produção literária, $e$ por transformações na nobreza portuguesa, como a nova hierarquização interna em função das ligações com a Corte, e a reivindicação de antepassados gloriosos, etc.

Há que sublinhar, também, que no século XIII uma visão negativa de Eva já estava consolidada no Ocidente (Saranyama, 1997; Dalarun, 1984:29-63; Fries, 2002:1-16), em especial entre os homens de saber. Como destaca Maria Izquierdo (2003:60):

a lo largo de los siglos XII y XIII se creó en las incipientes literaturas de las lenguas románicas el tema de la oposición Ave/Eva o lo que es lo mismo entre María, la Nueva Eva doadora de vida, y Eva, madre de la estirpe humana introductora de la muerte tanto física como espiritual en forma de pecado. 
É nesse contexto que a retomada da narrativa sobre a criação de Eva, preservada por séculos como monumento e expressa em miniaturas, afrescos, comentários bíblicos, tratados, sermões, etc, ganhou uso específico, preservando e/ou rompendo com tradições. ${ }^{4}$

Por que retomar tais textos? Por que nos colocamos diante desses mitos? Que dimensão devemos dar a esse lapso que nos separa do mito e do lugar de produção onde Hesíodo não é autor, mas pequeno agricultor e poeta, e que o texto hebraico do Gênesis encontra-se fundido com tantas outras tradições? Mas afinal de contas, onde nos situamos na comparação senão neste lapso, nesta costura? Necessário trazer à luz todas essas interrogações, pois a partir delas podemos situar o propósito de uma leitura histórica. Interessa-nos o gênero como saber $e$ a discussão sobre o modo como ele pode organizar narrativas tão profundamente políticas como a Teogonia e o Gênesis ocupando-se das prerrogativas dos seres e da criação de uma ordem soberana - como um projeto (uma estratégia) de conhecimento do lugar dos homens e mulheres na história da conformação das relações de poder entre os seres. Como projeto político, as narrativas nos interessam diretamente, vivamente; não como documentos ou testemunhos de uma outra história "social", mas como discursos historicamente construídos, enunciados, reapropriados, atuais.

\section{Em busca de Pandora}

As narrativas da criação de Pandora e de Eva têm como elemento central a produção de um corpo. Mas, se a carne é o traço significativo para a compreensão do corpo da mulher na narrativa cristã, o mesmo não acontece na narrativa hesiódica.

\footnotetext{
${ }^{4}$ A tradução do texto bíblico para o português não foi um fenômeno isolado. As primeiras bíblias romanceadas ibéricas começaram a surgir a partir do século XIII. Essas traduções foram realizadas a partir de três tradições textuais distintas: a latina, a hebraica e a galicana (Lopez Estrada, 1987:212).
} 
Nesta, o corpo da mulher não é criado, mas fabricado, e, para sermos precisos, é fabricado sob encomenda por Zeus, a fim de "presentear" os homens. Esse corpo vem do barro, é moldado como a argila por um artesão habilidoso. O fato das duas narrativas enfatizarem o surgimento de um corpo para fundamentar a existência de dois seres - o homem e a mulher levanta a questão da relação entre corpo e gênero.

Através dos estudos de T. Laqueur (2001), somos apresentados ao corpo de sexo único como figura central de um discurso médico na Antiguidade, além de uma representação triunfante no campo científico até pelo menos o século XVIII. Isto quer dizer que, ao organizar um conhecimento sobre o corpo humano, no mundo antigo foram produzidos discursos nos quais este corpo era compreendido como um só, como um continuum, do mais frio ao mais quente, do cru ao cozido, da mulher (ou menos masculino) ao homem (ou mais masculino). Mas o sexo único, característico do discurso de conhecimento e prática sobre o corpo na época clássica, não parece ter regido a compreensão do corpo de Pandora.

Não que devêssemos esperar uma correspondência direta entre a reflexão filosófica ou médica, delimitada e por vezes tardia, e uma só e única maneira de falar da realidade corporal. Contudo, é sempre importante realçar a descontinuidade não apenas entre o que se vê e o que está à frente dos olhos, ou entre o que se diz e o que se vive, mas entre tudo o que se pode dizer do que se vive. Assim sendo, não se trata de concluir que o corpo de sexo único, como saber, deve ser "relativizado". Acreditamos, de fato, que deve ser, antes, localizado, no contexto de um campo em que se produz conhecimento e se pratica a medicina, e, por isso, dentro de um processo de conformação institucional de longa duração. Isto quer dizer que o "projeto do sexo único" constitui uma prática discursiva dentre outras, descontínuas, num campo de poder/saber. O que nos leva à relevância do tema do corpo fabricado como um artefato. Nas duas narrativas hesiódicas do mito de Prometeu/Pandora, o corpo de mulher é dito ser outro, na 
origem. Mas em que consiste essa diferença? Qual o seu papel no jogo de definições (atribuições) de gênero?

Nas narrativas da Teogonia (vv.570-612) e de Os Trabalhos e os Dias (vv.55-82), a (mulher) é uma bela e deleitável forma de virgem, apresentada aos deuses e aos homens que se espantam ao ver a maravilha que foi criada. Mas essa maravilha é a contrapartida de um roubo, portanto, contrapartida de um dolo. Pelo fogo (roubado), "nasce" a primeira mulher (ardil incombatível). É com essa geração das femininas mulheres que a condição humana é selada na Teogonia. Em Os Trabalhos e os Dias, a condição humana se define quando Pandora - que agora tem um nome - abre a tampa de um jarro, liberando as penas, as dores, os pesares.

Mas o que é isso, a mulher? É "algo" dado a ver e que se admira, mas como tudo o que encanta, é exterioridade, invólucro de um engano, mal reverso de um bem, o mesmo tema que podemos encontrar no cavalo de Tróia da Odisséia. Essa obra de Hefesto apresenta-se como superfície de um corpo ${ }^{5}$, cujos elementos figurativos são a voz e a fala, a cabeça, o rosto e os membros, pescoço, peito. Deste corpo mostrado, apresentado e visto na Teogonia é dito ser plasmado em forma de virgem pudente $e^{6}$ e ter adornada a cabeça por lavores de diversos deuses.

Em Os Trabalhos e os Dias, Pandora surge com um comportamento humano, qualificado como dissimulada conduta (v.62), espírito de cão, mentiras e sedutoras palavras com humana voz e força (v.56). A primeira mulher ganha dos deuses um nome; assemelha-se de rosto (v.57) às deusas imortais; é bela e deleitável forma de virgem (v.58) e se apresenta conforme recatada virgem (v.66). Podemos observar que há aqui uma preocupação maior em "atiçar" a imaginação com detalhes do corpo figurado. Neste segundo poema, a primeira mulher parece ganhar vida ao se descrever um humor (ethos) e não apenas uma forma (eidos). Este

\footnotetext{
5 "Hó chrôs. (pánta dé hoi chrói kósmon ephérmose Pallàs Athéne" (v.76 Trab). 6 "Parthénoi aidoíei îkelon" (v.572).
} 
humor ela não tem na Teogonia, pois aí ela aparece toda exterioridade, oferta; como uma estatueta moldada e, assim, um ícone ou duplo.

Então, Pandora "faz figura" de bela, deleitável e recatada virgem, um modelo que precede a obra. Afirmamos isto não com base em uma necessidade lógica da narrativa, mas antes com o intuito de trazer para o centro da discussão a percepção dos ouvintes de Hesíodo. Para eles, essa primeira mulher, como presente dos deuses, vem conforme a párthenos (em ambos os poemas). É uma pseudo-virgem que os deuses ofertam aos homens, o que sugere que se evoca um modelo socialmente reconhecido, comum ao poeta como à audiência, já que somente a partilha dessa imagem da bela e recatada virgem torna possível conquistar o imaginário dos ouvintes para o encanto (thaûma).

A Teogonia conta a geração dos deuses e a instauração de diversos cortes na tecedura política de uma realidade comandada por Zeus; Os Trabalhos e os Dias fala da justiça que deve vigorar entre os homens. Temas fundamentais para procurar estabelecer uma compreensão da ordem humana, do lugar da humanidade (anthrôpoi) nessa realidade que é o quadro da vida de cada um. Por algum motivo, esse lugar, esse "quadro" da vida humana, se configura como uma divisão em dois: homem, mulher. Mas, que motivo é esse? Necessidade primária de explicar a existência de dois corpos entre os entes? Ansiedade primeva da partilha entre "machos" e "fêmeas" do quinhão da humanidade? O que significa esse "dois"?

Ao mito de Prometeu, os poemas de Hesíodo vinculam inextricavelmente a história de Pandora. Mas será que os poemas de Hesíodo focalizam a criação de um outro corpo, diferente por sua natureza de artefato fabril? Pondo-se de lado os elementos figurativos (cabeça, que se coroa; pescoço que se enlaça; membros) de corpo e comportamento, as palavras que designam essa realidade corpórea são de difícil determinação: aspecto, idéia, forma, superfície, podem designar a (superfície) do corpo da mulher tanto quanto a superfície de qualquer artefato. Não há, 
assim, preocupação em fazer dessa mulher um semelhante, pois a criatura nitidamente não vem do mesmo barro que os "homens comedores-de-pão". Então, diante dessa mulher não reina a apaziguadora visão da partilha do corpo humano, mas a perturbação do thaûma, do embevecimento que precede a boa armadilha.

O problema começa quando nos damos conta de que Hesíodo usa a metáfora da moldagem do vaso de argila num sentido muito claro de conformação a um modelo. Isto quer dizer que, embora fale da fabricação da mulher como a moldagem de um corpo, não é a realidade deste corpo que está em questão; o problemático não é de forma alguma que o corpo das mulheres configure uma forma de alteridade, mas que o gênero feminino seja, na origem, um engodo absolutamente necessário, por ser a contrapartida (divina) do roubo do fogo no qual os homens estão implicados. A possibilidade do engano, ou a aparência humana que seduz os desavisados, a ambiguidade, enfim, é o que perturba. Em outras palavras, o perigo está na semelhança, não na diferença.

Daí, então, que Pandora (ou aquela da qual descendem as gunai) não representa o primeiro corpo de mulher, mas sim uma "coisa" que se assemelha formalmente (como corpo e como comportamento) às deusas como às virgens, ou seja, uma imagem, um semblante suficientemente atraente para cegar deuses e homens para um estratagema. Na origem do sacrifício, como forma de comunicação entre homens e deuses, contada na Teogonia como razão do malogro de Prometeu, está não simplesmente a imposição de um corpo outro, diferente, como "castigo" aos seres humanos, todos masculinos comedores de pão em seu "pequeno Éden" - ou seria melhor dizer, na sua idade do ouro? O lugar dos homens neste mundo é, também, instaurado pela injunção ao casamento, razão de ser (e de doar) da "geração das femininas mulheres". Pois é disto que se trata: a "coisa" dada aos homens pelos deuses reunidos é a esposa. 
É com esta última, e não com o sexo feminino, que se instauram distinções - entre homens mortais e deuses imortais; entre homens comedores-de-pão e feras "que a terra e o mar nutrem"; entre homens e raça das mulheres. A geração das "femininas mulheres" como tema, refere-se, portanto, à presença da esposa na casa (espaço habitado) dos homens.

$\mathrm{Na}$ narrativa de ambos os poemas, o que se segue à fabricação da primeira feminina mulher são, de fato, considerações sobre sua presença na casa dos homens que as recebem como dons-esposas. Na Teogonia (v.591 e segs.), o tema da coabitação enseja a censura contra as esposas que consomem dentro de casa os recursos que os homens a elas trazem, como os zangões nas colméias. Como contraponto dessa "mulher-zangão", pode existir a "cuidosa esposa" que, na tradição da Elegia de Semônides de Amorgos (século VII a.C.), vem a ser a enigmática mulher-abelha, a mélissa, única a qual censura não se liga e que se torna parceira dos homens (Andrade, 2001). Difícil é, contudo, a distinção, pois todas descendem da "raça das mulheres", criadas como armadilha, não como dádiva. Em Os Trabalhos e os Dias (v.89 e segs.), Pandora abre a tampa do jarro que traz como seu dote assim que entra na casa do homem desavisado (Epimeteu). Nada de bom sai desse jarro, somente os males que agora erram na mesma extensão em que a humanidade habita, prendendo-se a esperança (Elpís) que, curiosamente, também faz parte do dote. Ambigüidade da coexistência com as mulheres: nas duas narrativas, elas carregam consigo a (possibilidade) do "bem".

"Mal reverso de um bem": mulher como contrapartida do fogo ou ainda má e boa esposa, má e boa união? O que o tema da coabitação nos mostra com certa clareza é a centralidade do casamento, e por isso mesmo a centralidade da figura daquela mulher - e não de todas - que coabita com um homem em sua casa, dividindo com ele uma tarefa crucial: a de gerir o patrimônio, melhor dizendo, a gestão do oîkos mediante uma divisão genderificada das tarefas. A coabitação é o problema, a 
divisão da gestão da casa é a tarefa que parece produzir a necessidade de compreender a presença da esposa.

Os efeitos de tal narrativa no meio em que Hesíodo vivia, entre aqueles com quem dialogava, junto às audiências diante das quais ele os apresentava, estão perdidos para nós. Mas a significativa correspondência do problema da coabitação e do casamento nas narrativas de Hesíodo e nos diversos textos da Atenas clássica, é um convite ao aprofundamento - uma tarefa gigantesca, diga-se de passagem. Não poderíamos, contudo, deixar de citar alguns exemplos de forma pontual.

Em torno de 430a.C., Eurípides fez a primeira apresentação da peça Medeia nas Grandes Dionisias atenienses, e desde então a figura euripidiana de Medeia jamais abandonou o imaginário ocidental. Nesta peça, Eurípides faz do conflito entre Medeia e Jasão pelo casamento desfeito uma contenda quase ontológica entre os gêneros feminino e masculino, conflito este que ultrapassa até mesmo as barreiras da cidadania, $e$ faz com que as mulheres de Corinto (coro) permaneçam solidárias com Medeia, em toda a sua vingança (matar a princesa noiva de Jasão, assassinar o rei, e seus próprios filhos). A ligação com a poesia, e particularmente com Hesíodo (e Semônides de Amorgos), é evidenciada por um canto coral, em que o coro afirma que vai "contra-ecoar o hino do gênero masculino", prometendo que, depois disso, "não mais díssona fama será das mulheres"; "as musas de antigos cantores calarão os hinos do meu descrédito" (vv.410-445).

Cerca de cinqüenta anos depois, Xenofonte escrevia o tratado $O$ Econômico, no qual dedicaria cinco capítulos ao casamento e à formação da esposa. A figura ideal desta última é a da melissa, ou "rainha das abelhas", e se propõe o casamento como parceria na coabitação, estabelecendo que a lei, os deuses, e a natureza fazem com que a mulher, de corpo e alma, seja feita para o interior da casa, e o homem, de corpo e alma, seja feito para o exterior, em uma relação que deve ser complementar.

Por fim, um pouco depois de Xenofonte, Aristóteles voltaria ao assunto na Política, livro I, estabelecendo, primeiro, que a 
união macho-fêmea é natural e necessária para a continuidade da espécie (1252a-b), sendo uma das primeiras formas de comunidade natural, e nisso está a coabitação (Id.ib.). Mas mais adiante diz que, se a primeira forma humana de comunidade é a família e a família é formada por três partes - senhor-escravo, pais-filhos, marido-esposa - que "comem à mesma manjedoura", ao contrário de escravos, sobre os quais o poder do chefe da casa é despótico, e dos filhos, sobre o qual ele é monárquico, a tutela do homem sobre a mulher é conforme a política. Isto pode não significar, necessariamente, democracia, mas com certeza, significa uma relação com entre livres e iguais, pois somente entre estes últimos o poder pode ser exercido politicamente (1259a-b).

Era uma vez um estratagema imbatível do soberano entre os deuses. O estratagema fez das virgens belas e deleitáveis de se ver e, dessas belas e deleitáveis formas de virgens, logrou fazer as esposas. Bem ou mal, as esposas são seres que dividem com os homens as tarefas centradas no oîkos. Eis uma das hipóteses que gostaríamos de aprofundar no futuro. Uma segunda hipótese referente à leitura da criação de Pandora como figuração de um corpo, precisa discutir por que a esposa que divide a tarefa de gerir um patrimônio deve aparecer como corpo plasmado, fabricado, projetado como estratagema, como "cavalo de Tróia". Um corpo materialmente diferente, enquanto formalmente semelhante; um pseudos que, no mínimo, enfraquece a diferença, enquanto desautoriza a semelhança.

\section{Eva e a Bíblia Medieval Portuguesa}

Como no Gênesis hebraico e latino, há, na versão portuguesa, duas narrativas de criação do homem e mulher. Essa dupla narrativa da criação explica-se pelo processo de composição do Pentateuco hebraico (Gotwald, 1988:139-143), formado por tradições textuais diversas que, posteriormente, foram reunidas. Os capítulos que narram esses episódios são, na versão 
portuguesa em estudo, os de número VII, IX, parte do X, e XII. Os relatos relacionados à queda, ou seja, a desobediência de Adão e da primeira mulher que os levou à expulsão do paraíso, estão presentes nos capítulos XIII, XIV, XV, XVI (ver apêndice).

Na primeira narrativa, apresentada no cap.VII, a criação do homem e da mulher ocorre simultaneamente. Nesse relato, como uma adição à Vulgata ${ }^{7}$, o homem é criado com uma alma, o que o torna a "ymagem" de Deus. Sem dúvida, o texto usa o termo "home", nesse capítulo, com o sentido de ser humano. Essa interpretação é corroborada com a idéia que vem a seguir: Deus criou macho e fêmea, sublinhando as diferenças corporais entre ambos. ${ }^{8}$ Esse fato é destacado nesse mesmo capítulo, pois, após a criação, Deus legitima a relação heterossexual entre os humanos, fundamentada na necessidade da procriação, e aponta para uma relação assimétrica: o homem e a mulher deveriam dominar todos os demais seres vivos, as criaturas inferiores que não eram a "ymagen" de Deus, por não possuírem alma.

A segunda narrativa da criação divide-se em dois capítulos. No IX relata-se a criação do homem $e$ no XII a da mulher. Segundo o texto português, Deus "formou" o corpo do homem do "limo da terra" e deu-lhe "spiraçõ de vida", ou seja, dotou-lhe de uma alma, que foi criada de "nemigalha", isto é, de coisa alguma. Assim, o homem, distinto dos animais, possui um corpo material $e$ uma alma imaterial, o que o torna superior aos demais e justifica porque coube a ele guardar o paraíso. O texto ainda acrescenta,

\footnotetext{
7 As comparações do texto português com o da Vulgata justificam-se, pois essa última era considerada pela Igreja Romana a versão oficial do texto bíblico. Face à expansão das traduções da Bíblia em romance $e$ o perigo do surgimento de heresias, a Igreja buscou reforçar a autoridade do texto da Vulgata, proibindo a leitura das bíblias em língua vulgar. Sobre essa questão ver Fernandez Lopez (2003).

8 Segundo Phipps, o termo hebraico presente no relato do Gênesis 1, 27, haadam, indica que não se tratava de um nome pessoal, mas de uma denominação genérica. Compreendemos que esse sentido geral foi mantido na Vulgata e na versão portuguesa em análise. (1988:35).
} 
como um esclarecimento, que o homem já fora criado adulto e a sua morte era uma possibilidade, o que não figura na Vulgata. A inserção dessa explicação é, certamente, fruto da racionalidade dos homens de saber de fins do medievo, que exigia uma certa lógica narrativa.

O tema morte ganha relevo no capítulo $\mathrm{X}$, no qual o paraíso é descrito. Nele a morte é associada aos frutos das árvores da vida e da "sciencia do bem e do mal". Deus proíbe o homem de comêlos; se o fizer, morrerá. Como a mulher ainda não fora criada nesse ponto da narrativa, é possível inferir que essa ordenança foi dirigida unicamente ao homem. ${ }^{9}$

No capítulo XII, a idéia da criação da mulher parte de Deus, que quer dar ao homem uma "ajudoiro semelhavil" e apresenta detalhes diferentes face ao texto da Vulgata. Na narrativa em português, Deus mandou que Adão desse nome a todos os animais com um objetivo claro: para que ele percebesse que dentre os animais não havia nenhum que lhe era semelhante. Deus, então, fez o homem dormir e tomando uma de suas costelas, "feze dela molher". Vale destacar que o texto, mantendose fiel à Vulgata, não fala que a mulher recebeu uma alma. $\mathrm{Ou}$ seja, o corpo da mulher foi fabricado por Deus, mas da matéria do corpo do homem.

O homem reconhece a mulher como osso dos seus ossos $e$ carne da sua carne e a nomeia, como fez com os outros animais. Ele a denomina como Virago, termo que na Bîblia portuguesa e na Vulgata é explicado como "feita de varão". Ainda no capítulo XII, em um discurso atribuído ao personagem Adão, acrescenta-se que por causa da mulher o homem deixaria seus pais e "seram dous em hua carne". Ou seja, trata-se de uma clara referência ao casamento, apresentado como uma idéia humana face à obra

${ }^{9}$ Essa conclusão é reforçada pelo capítulo XI, que informa que o homem foi colocado no paraíso após ter sido criado em outro lugar, bem como reintera a ordem dada por Deus para que o homem não comesse do fruto. 
divina da criação. Esse fato é reforçado no capítulo seguinte, quando Adão passa a ser identificado como "marido".

Face aos capítulos dedicados à criação, são abundantes os referentes à queda, cinco ao todo. Neles, alguns elementos são dignos de destaque, por conta de sua diferença frente à Vulgata. Em primeiro lugar, a serpente é identificada com Lúcifer, que fala pela boca do animal. Aqui é introduzida a figura do "inimigo", o diabo, que nesse momento ganha relevo na teologia $e$ arte ocidentais. ${ }^{10} \mathrm{Em}$ segundo, é dada uma razão para que a serpente ofereça o fruto proibido a Eva: Lúcifer resolve tentar a mulher porque tem inveja do homem e quer que ele seja "lançado fora" do paraíso. Em terceiro, a mulher é qualificada como soberba, o que explica porque ela aceitou o fruto: segundo a serpente/Lúcifer, se ela comesse do fruto ficaria semelhante a Deus. Em quarto, a mulher é que dá o fruto a Adão, mas ele só o come porque percebe que, após digeri-lo, a mulher não morrera, concluindo, portanto, que Deus proibira o consumo do fruto somente para assustá-los. Em quinto, após comerem do fruto, perceberam que estavam nus; ficaram envergonhados, $e$ "sentirom primeiro o movimento contrairo aa razom enos membros da geeraçom".

A partir desses dados, a que conclusões podemos chegar? Em linhas gerais, podemos apontar que os capítulos analisados parecem explicar porque os homens $e$ as mulheres apresentam diferenças corporais; como essas diferenças são importantes para a preservação da espécie; como surgiu o casamento; porque é legítima a punição para a desobediência; como a desobediência $e$ o sofrimento estão ligados e quais os papéis que devem ser ocupados pelos homens e mulheres no casamento.

A Bíblia portuguesa reforça a idéia de que desde a criação homem e mulher são corporalmente distintos. Isto fica patente nos dois relatos da criação. No primeiro, ainda que informando que

\footnotetext{
${ }^{10}$ Sobre o diabo no medievo ver, dentre outros, Link (1998), Muchembled (2001), Baschet (2002:325-355), Russel (2003).
} 
Deus criou o homem $e$ a mulher no mesmo momento e à sua imagem, é destacada a diferença anatômica. Segundo BIRD (1981:132), esse destaque visa sublinhar a natureza semelhante dos humanos e dos animais. Mas, se no corpo se assemelham aos animais, pela alma os homens são semelhantes a Deus. Essa similitude com os animais, contudo, pode levar o homem a incorrer em erro, como veremos a seguir.

$\mathrm{Na}$ segunda narrativa, homem e mulher são diferentes quanto à matéria de que são feitos - homem, do limo e do sopro divino; mulher, da costela de Adão -, e quanto às suas funções o homem guarda o Paraíso, a mulher o ajuda. O próprio termo usado - semelhavil - traduz a idéia de que apesar de criados por Deus há uma hierarquização entre eles. Primeiro surgiu o homem, cujo corpo foi modelado com a terra, mas cuja alma veio diretamente de Deus. A mulher, apesar de ter sido feita por Deus, deriva do homem, surge depois dele e em função dele, já que foi criada para ajudá-lo, e não recebeu o sopro de Deus, a alma. Há, portanto, uma evidente hierarquia: Deus primeiro cria a terra. A partir do limo cria o homem e dá-lhe o sopro da vida. Do corpo do homem, Deus faz a mulher.

Há que sublinhar que dentro da lógica do texto em estudo, a criação da mulher não é um castigo, mas um bem. Sendo feita por Deus, a origem de todo o bem, ela não poderia ser um mal. Essa idéia é reforçada no fato do texto português optar por manter o nome Virago dado à mulher por Adão. Segundo Cláudio Moreno (2006), "etimologicamente virago nunca foi um feminino genérico de varão, que pudesse ser aplicado a qualquer mulher". Esse termo, derivado do latim vir, originariamente significava "mulher semelhante ao homem e, portanto, forte, destemida, heróica", e era usado para denominar mulheres heroínas. Logo, o seu uso no texto figura para qualificar a mulher positivamente, porque proveniente do homem e, portanto, semelhante a ele.

A mulher e o homem, segundo o relato em análise, foram colocados no Paraíso, espaço também criado por Deus. E como era esperado de todos os seres viventes criados, eles deveriam 
crescer e multiplicar. A procriação é, portanto, uma ordem divina, o que legitima as relações sexuais mesmo antes da queda.

O texto da Bíblia Medieval Portuguesa traça, contudo, uma relação entre a criação da mulher da matéria do homem, a prática sexual heterossexual e o casamento. A mulher, como era a única dentre os seres criados semelhante ao homem, era a única com quem esta união carnal seria possível. Com um objetivo claramente didático, o texto qualifica um dado comportamento sexual como natural e aprovado por Deus e condena os "contra a natureza". De forma explícita recrimina as relações sexuais com animais e a homossexualidade. Ou seja, o texto constrói assimetrias que se relacionam com os papéis na reprodução e, por extensão, com as relações sexuais. O homem não pode procriar com os animais, porque são inferiores a ele, não possuem alma. Mas também não pode procriar com outros homens, porque possuem o mesmo corpo. Logo, há que procriar e relacionar-se sexualmente com uma semelhante, que deriva dele, mas não é a sua imagem fiel. Assim, associado à reprodução, o casamento torna-se um elemento fundacional, anterior à queda do homem $e$, conseqüentemente, necessário.

O matrimônio é apresentado como um rompimento do homem com a família que o engendrou para a criação de uma nova, pela união com uma mulher. ${ }^{11}$ Vale destacar que é justamente no período em que essa obra circula em Portugal que a Igreja Romana busca introduzir no Ocidente o seu modelo de casamento, monogâmico e heterossexual, sacralizando-o $e$ legitimando-o pela necessidade da procriação. Nesse sentido, essa narrativa reforça essa iniciativa.

Mesmo antes da "queda", há uma nítida relação hierárquica entre homens e mulheres. Deus coloca o homem como o responsável pelo paraíso, permite que ele dê nome a todos os

\footnotetext{
11 João Calvino já apontava que Gênesis 1,27 "existe para exaltar o vínculo do matrimônio". Contudo, no que o reformador via complementaridade entre homens e mulheres, verificamos assimetrias (Schmitt-Pantel, 2001:138).
} 
animais da terra; dá ordens diretamente a ele, cria-lhe uma "ajudoiro". Mas essa hierarquização se confirma e ganha novo contorno após o consumo do fruto proibido.

Segundo o capítulo XIV, ao caminhar pelo paraíso e perceber que Adão e sua mulher se escondiam, Deus dirige-se primeiramente ao homem e pergunta-lhe o que ocorreu. Só depois Deus fala com a mulher. Ao distribuir as punições, a hierarquia é novamente seguida por Deus, ainda que inversamente. A serpente é a primeira a receber a sua pena. Ela, além de ter que se arrastar doravante no solo, será inimiga da mulher, que irá feri-la. A mulher, por sua vez, ficará sob o domínio do homem e com dor terá filhos. A punição do homem se estende à natureza, que lhe será hostil, pois produzirá cardos e espinhos; ele terá que trabalhar para se alimentar e conhecerá a morte.

Marcando essa mudança nas relações entre o homem, a mulher e natureza, Adão, "chorando a mizquindade da linhagem", dá um novo nome à mulher, que passa a denominarse Eva. O sentido do nome não é apresentado no texto, mas é associado ao sofrimento. Ou seja, com a desobediência a mulher deixa de ser ajudadora e semelhante ao homem, uma Virago, para tornar-se um ser submisso e sofredor. A hierarquia, então, é transformada pela noção de dominação. Devido à desobediência, a relação hierárquica, mas até então harmônica, entre o homem, a mulher e a natureza, se quebra. Todos serão punidos, mas caberá ao homem dominar a mulher.

Ainda como resultado da desobediência, o homem e a mulher ganharam consciência de sua nudez e passaram a fazer uso de seus corpos movidos não mais pela razão, mas pelo desejo. $\mathrm{O}$ texto parece reforçar o caráter negativo que o corpo e o sexo ganharam com a desobediência: eles deixaram de ser usados somente para o fim da procriação, mas também para o prazer.

$\mathrm{O}$ texto da Bíblia Medieval Portuguesa, reiterando elementos tradicionais $e$ incluindo alguns detalhes explicativos, constrói o feminino e o masculino como semelhantes quanto à matéria, mas hierarquicamente posicionados, reiterando, assim, as 
diferenças de gênero. Também legitima a dominação masculina, fruto do pecado da soberba da mulher. Por outro lado, o texto apresenta uma visão positiva do casamento, tanto antes quanto depois da "queda", mas no qual a mulher ocupa uma posição inferior ao homem, é sua "ajudadoira", ainda que personagem central para a reprodução. Nesse relato, o modelo de casamento ideal, proposto pela Igreja Romana para os leigos, é reforçado: ele é monogâmico, heterossexual, entre seres responsáveis e visa a reprodução. Além disso, propõe papéis específicos para homens e mulheres: aos homens cabe o sustento da família e à mulher a procriação.

\section{Conclusões}

Entre os dois relatos, as diferenças são muitas $e$ as semelhanças tentadoras. Então, uma cautela é necessária: Pandora não é Eva; Prometeu não é Adão. Contudo, o fato de que em dois sistemas culturais profundamente diferentes fala-se de criação, de lugar da humanidade no mundo, através de narrativas em que esse lugar é explicado na partilha do ser humano entre masculino e feminino, merece uma atenção mais aprofundada. Acreditamos que não devem ser feitas de forma apressada interrelações que, de fato, expressam mais as releituras posteriores dos mitos do que os efeitos de sentido produzidos em seu contexto de enunciação, como nos alerta Phipps (1988). E assim, devemos concluir o ensaio inserindo as narrativas em contextos sociais em que, de algum modo, justificam diferenças e dão significado a relações de poder.

Sob esta perspectiva, as narrativas se abrem em duas temáticas comuns: a fabricação do corpo para uma união "cooperativa" no casamento e sua inserção em um contexto de estabelecimento e desafio aos poderes constituídos em acordo com uma ordem divina. Mas uma diferença é fundamental: enquanto é impossível compreender a narrativa hesiódica no âmbito de uma doutrina religiosa, o texto do Gênesis da versão 
portuguesa medieval só pode ser interpretado no seio de uma doutrina delimitada. Ele serviu, em grande medida, para difundir o casamento como um dos sacramentos da Igreja Romana.

Os relatos da criação presentes no Gênesis foram a base de muitas discussões no medievo. Tais reflexões estavam longe de serem uníssonas. $\mathrm{O}$ texto analisado, assentado na autoridade da tradição bíblica, ainda que apreendido de forma criativa, acabou por reforçar, no Reino Português do final da Idade Média, assimetrias entre os animais, as mulheres e os homens e uma dada moral sexual. Vale assinalar que tais hierarquias são estabelecidas antes dos relatos da queda e, portanto, não se vinculam ao pecado, mas à organização social, ao casamento, e às relações entre os humanos e a natureza. Contudo, com a desobediência surge a dominação masculina e rígidas diferenças entre os papéis ocupados por homens e mulheres no casamento. Assim, cabe a mulher ter filhos e ao homem sustentar a família. Criadas para serem ajudantes, as mulheres se tornam seres inferiores que devem ser tutelados e que sofrem para cumprir sua missão de parir.

Nesse sentido, acreditamos que a Bíblia Medieval Portuguesa trata, prioritariamente, de corpos e de gênero. Corpos que são criados por Deus de forma diferente, mas que são semelhantes e complementares para a preservação da espécie. Corpos que, com a queda, ganham novas significações de gênero. $\mathrm{O}$ corpo masculino passa a ser o dominador: precisa vencer a natureza para dela tirar seu pão e controlar a mulher para garantir a perpetuação da espécie.

A história da bela forma de virgem da qual descendem todas as mulheres é bem diferente. Ela nasce outra, e a alteridade será a marca da estirpe feminina. Marca positiva e não negativa: o corpo feminino é banhado na dynamis do dolo que o fabricou. Daí que seu sexo seja, sempre, uma ameaça cuja dominação ao homem escapa. Talvez porque lhe falte a consagração de uma instituição a partir da qual emana o discurso correto e verdadeiro, em acordo com a doutrina. 
Seja como for, assim como a história de Eva, aquela de Pandora entrou para o circuito das idéias com as quais a naturalidade do gênero se apresentou às gerações futuras. E dessa maneira contribuiu para consagrar diferenças $e$ justificar as assimetrias nas relações de poder. Mas ao menos no contexto da polis clássica, o mito de Pandora diz menos respeito à dominação sexual da mulher pelo homem do que à imagem de superioridade sobre outrem que o cidadão projeta de si mesmo. ${ }^{12}$ Ao separar duas estirpes, duas "raças", a tradição hesiódica desautoriza a mistura entre masculino e feminino presente em tradições mais antigas, e abre o campo em que se favorece o postulado da virilidade como apanágio dos homens da cidade. Eis uma forma primária de significar relações de poder. Curiosamente, essa possível manobra deixa a descoberto todo um campo político que pode ser franqueado pelas "femininas mulheres", na medida em que elas são ao mesmo tempo o paradigma do que deve estar fora, mas seres necessariamente de dentro, por desígnios do Cronida, como diz Hesíodo.

\section{Referências bibliográficas}

ANDRADE, Marta. A Cidade das Mulheres. Cidadania e alteridade feminina na Atenas Clássica. Rio de Janeiro, LHIA, 2001.

ANTUNES, José. Bíblia. In: LANCIANI, Giulia e TAVANI, Giuseppe. (orgs.). Dicionário da Literatura Medieval Galega e Portuguesa. Lisboa, Caminho, 2000, pp.85-88.

BASCHET, Jérôme. Diabo. In: LE Goff, Jacques e SCHMITT, Jean-Claude. (orgs.) Dicionário Temático do Ocidente Medieval. Bauru, EDUSC, 2002 [1999], 2 vol., vol.1, pp.325-355.

\footnotetext{
12 “(...) Sob a evidência da exaltação do anèr, eu decifro o cuidado em definir o homem cidadão por uma virilidade que nada de feminino poderia atrapalhar. $\mathrm{E}$ nesse cuidado vejo o esforço durável do político para rejeitar para suas margens uma tradição adversa ou ao menos outra. Uma tradição, também grega e que, da epopéia homérica às lendas heróicas, postula que um homem digno deste nome é mais viril abrigando em si mesmo a feminilidade" (Loraux, 1989:7-26).
} 
BIRD, Phyllis. A. Male and Female He Created Them: Gen 1:27b in the Context of the Priestly Account of Creation. Harvard Theological Review (74), Cambridge, apr. 1981, pp.129-159.

BouRdieu, Pierre. A Dominação Masculina. Rio de Janeiro, Bertrand do Brasil, 2002 [1998].

DALARUN, Jacques. Olhares de clérigos. In: DUBY, Georges e PERROT, Michelle. (dir.) História das Mulheres no Ocidente. Porto, Edições Afrontamento, s/d [1990-1992], vol. 2: A Idade Média, pp.29-63.

FERNÁNDEZ LÓPEZ, Sergio. Lectura y prohibición de la Biblia en lengua vulgar. Defensores y detractores. León, Universidad de León, 2003.

FRIES, Maureen. The evolution of Eve in medieval French and English religious drama. Studies in Philology (99), Chapell Hill, 2002, pp.116.

GoTTWALD, Norman. Introdução sócio-literária à Bíblia hebraica. São Paulo, Paulinas, 1988 [1985].

Headlam, Walter. Prometheus and the Garden of Eden. Classical Quarterly (28), Cambridge, 1934, pp.63-67.

Hesíodo. Teogonia. São Paulo, Iluminuras, 1991 [Trad. J.A.A. Torrano]. . Os Trabalhos e os Dias. São Paulo, Iluminuras, 1991 [Trad. Mary de Camargo Neves Lafer].

KoCKA, Jürgen. Comparison and beyond. History and Theory (42), Oxford, 2003, pp.39-40.

IZQUIERDO, Jose Maria. Ave/Eva: comentarios acerca de una tipología artística bajo medieval. Romansk Fórum (27), Oslo, 2003, pp.59-70.

LACHS, Samuel. T. The Pandora-Eve Motif in Rabbinic Literature. Harvard Theological Review (67), Cambridge, 1974, pp.341-345.

LAqueuR, Thomas. Inventando o Sexo. Corpo e Gênero dos Gregos a Freud. Rio de Janeiro, Relume-Dumará, 2001 [1990].

LINK, Luther. O Diabo: a máscara sem rosto. São Paulo, Cia das Letras, 1998 [1995].

LÓPEZ ESTRADA, Francisco. Introducción a la Literatura Medieval 
Española. $5^{\mathrm{a}}$ ed. Revisada, Madrid, Gredos, 1987.

LORAUX, Nicole. Les Enfants d'Athéna. Idées Athéniennes sur la Citoyenneté et la division des sexes. Paris, La Découverte, 1990.

Gallimard, 1989.

. L'Opérateur Féminin. Les Expériences de Tirésias. Paris,

MARTins, Mario. A Bíblia na Literatura Medieval Portuguesa. Lisboa, Instituto de Cultura Portuguesa, 1979.

Megale, H. (ed.) O Pentateuco da Bíblia Medieval Portuguesa. São Paulo, EDUC/IMAGO,1992.

MoRENO, C. Virago, varoa. Disponível em http://www. sualingua.com.br/01/01_virago.htm [consultado em 23/06/2006].

MuCHEMBLED, Robert. Uma História do diabo. Séculos XII ao XX. Rio de Janeiro, Bom Texto, 2001 [2000].

NASCIMENTO, Aires. Bíblia: traduções para o português. In: Lanciani, Giulia e Tavani, Giuseppe. (org.) Dicionário da Literatura Medieval Galega e Portuguesa. Lisboa, Caminho, 2000, pp.88-92.

PHIPPS, William. E. Eve and Pandora Contrasted. Theology Today (45), Princeton, 1988, pp.34-48.

REDFIELD, James. O homem e a vida doméstica. In: VeRNANT, JeanPierre. (ed.) O Homem Grego. Lisboa, Presença, 1994 [1991], pp.147-171.

RuSSEL, Jeffrey. Lúcifer: o diabo na Idade Média. São Paulo, Madras, 2003 [1984].

SARANYAMA, Josep Ignasi. La discusión medieval sobre la condición femenina (Siglos VIII XIII). Salamanca, Universidad Pontifícia de Salamanca, 1997.

SCHMITT, Jean-Claude. (dir.) Éve et Pandora. La création de la femme. Paris, Gallimard, 2001.

SCHMITT-PANTEL, Pauline. "A criação da mulher": um ardil para a história das mulheres? In: MATOS, Maria Izilda \& SOIHET, Raquel. (orgs.) O corpo feminino em debate. São Paulo, Editora da Unesp, 2003, pp.129-156. 
Mito e gênero

ScOTT, Joan. Gender as a Useful Category of Historical Analysis. In: Gender and the Politics of History. New York, Columbia UPress, 1999, pp.28-50.

SECHAN, Louis. Pandore, l'Eve grecque. Bulletin de l'Association Guillaume Bude (23), Paris, 1929, pp.3-36.

TEGGAR, Frederick. The argument of Hesiod's Works and Days. Journal of History of Ideas (8), Philadelphia, 1947, pp.45-77.

VEYNE, Paul. O Inventário das Diferenças. São Paulo, Brasiliense, 1983 [1976]. 